\title{
Providing resistance of protection means on the soft adjoining rocks
}

\author{
Serhii Nehrii ${ }^{1, *}$, Tetiana Nehrii $^{1}$, Sergey Kultaev $^{2}$, and Oksana Zolotarova ${ }^{1}$ \\ ${ }^{1}$ Donetsk National Technical University, 85300, Pokrovsk, Shybankova Sq., 2, Ukraine \\ ${ }^{2}$ State Enterprise "Mine named after M.S. Surhai", 85670, Vuhledar, Ukraine
}

\begin{abstract}
Problems of maintaining of development the roadways in conditions of the soft adjoining rocks have been considered. The engineering solution for resistance of rigid protection means by building local reinforced zones under these constructions has been suggested. Combination of protection means and reinforced zones has reduced roof rock subsidence. The operation of protection means and reinforced zones as a holistic construction has been viewed on physical and numerical models. Based on simulation results, the efficiency of deepening of protective means below the footwall, the alternative to which can be creation of the reinforced zones in the footwall rocks, has been established. Factors that have to be taken into consideration when setting parameters of a local reinforced zone under the protective means have been identified.
\end{abstract}

\section{Introduction}

The development of prospective coal-bearing areas of the Donbas involves the coal extraction of grades $D$ and $G$ in difficult mining and geological conditions, which are characterized by an increase in the depth of mining, soft adjoining rocks, waterlogged and disturbed coal-and-rock strata, etc. [1]. Working systems that require protection of the development roadways behind the breakage face are mostly taken in such conditions. For such roadways, it is envisaged to leave the pillars or to build artificial protective constructions on the boundary between the roadways and the mined-out space in order to provide sufficient support to the roof rocks, which remained without it as a result of coal extraction, and influence with their weight on the barring. But, as experience shows, these measures are not always effective, and roadways require repairing. For example, the work [2] gives the results of experimental observations and shows that at a certain distance from the face technological pillars work as intensity concentrators and help to extrude the footwall rocks into the face as well as to change its contours. Studies [3, 4] state that the effect of rigid protection means on the footwall rocks is similar to extrusion of plastic rocks from beneath a die, which pushes them towards free space. The use of pliable protective constructions does not let to fully provide the operational state of the roadways, since it allows significant displacement of the roof rocks [5,6]. Thus, the issue of providing the operational state of development roadways behind the faces in conditions of soft adjoining

*Corresponding author: serhii.nehrii@donntu.edu.ua 
rocks is not solved. Therefore, the aim of the work is to substantiate and develop engineering solutions to provide resistance of protection means on the soft adjoining rocks.

\section{Methods}

On the development roadway in the area of influence of temporary bearing pressure from the active face, the shift of the roof rock depends on the physical and mechanical characteristics of the host massif, seam thickness, as well as the parameters of the roadway, the final section of the face and protective means [7]. These factors, for different conditions, have different effects on the final result, but many scientists agree that at this stage of exploitation of the roadway they should be attributed to: seam thickness, the type of the footwall rock, the stratification depth and the nature of the protective means. This is clearly seen in the expression for the determination of displacement in the roadway of $U$, which is the following [8]:

$$
U=-78+0.066 z+4.3 h_{\mathrm{s}}(P I)+7.7[10(F I)]^{-0.5} \%
$$

and shows that with increasing the depth of development $z$ (м) and the seam thickness $h_{s}$ (м) the vertical convergence in the roadway increases. Separately, it is necessary to note the stiffness index of the protective strip PI (units) and the thickness of the footwall rocks $F I$ (units), which have different values for different means of protection and types of footwall rocks $(P I=1$ for a hard strip, $P I=2$ for a rock strip or wood chock, and $P I=3$ in the absence of a protective construction; $F I=1 . .6$, where the smallest value corresponds to hard rocks, and the largest - to soft ones). It follows from the expression that an increase in these indicators leads to an increase in roadway displacement.

It is naturally that the more rigid the protective construction and the more resistant the footwall are, the less the loss of the cross section of the roadway is. A more complicated situation is when the bearing capacity of the rigid protective means is leveled by the soft footwall rocks. In our opinion, it is necessary to create a resistant construction in the sole, which could withstand the weight of the rocks hanging over the means of protection. This construction must be of a special shape, with limited dimensions and harder than surrounding rocks. Thus, under the protection means, a local reinforced zone is created.

The definition of a local reinforced zone was first proposed by prof. M.M. Kasian [9], which was understood to mean a limited-sized zone in the area of destroyed rocks around the mine roadway, which was located between the wedge-shaped sectoral sections and strengthened with anchors and bonding mixtures. Later, the studies of prof. I.G. Sakhno $[10,11]$ appeared, where the local zone at the footwall, which was created by means of selfexpansion of a mixture or hardening solutions in holes, was considered.

The local reinforced zone is located in the soft rocks under the protection means to provide their resistance. This construction is consolidated by setting anchors or by pumping bonding mixtures, and is able to withstand the loads affecting on them by the protective means. Possible design of local reinforced zones is shown in Figure 1. The shape of the zone can be any. If it is correct (rectangular, triangular, etc.) (Fig. 1 a, b, c, d, e), there are difficulties with providing the necessary shape. The more realistic shape can be elliptical with the orientation of the largest axis perpendicular (Fig. $1 \mathrm{f}$ ) or parallel (Fig. $1 \mathrm{~g}$ ) to the foot surface. In addition, the load from the roof on the protective means is usually asymmetric, so the local area can be asymmetric about the axis of the protective means (Fig. 1 h). 

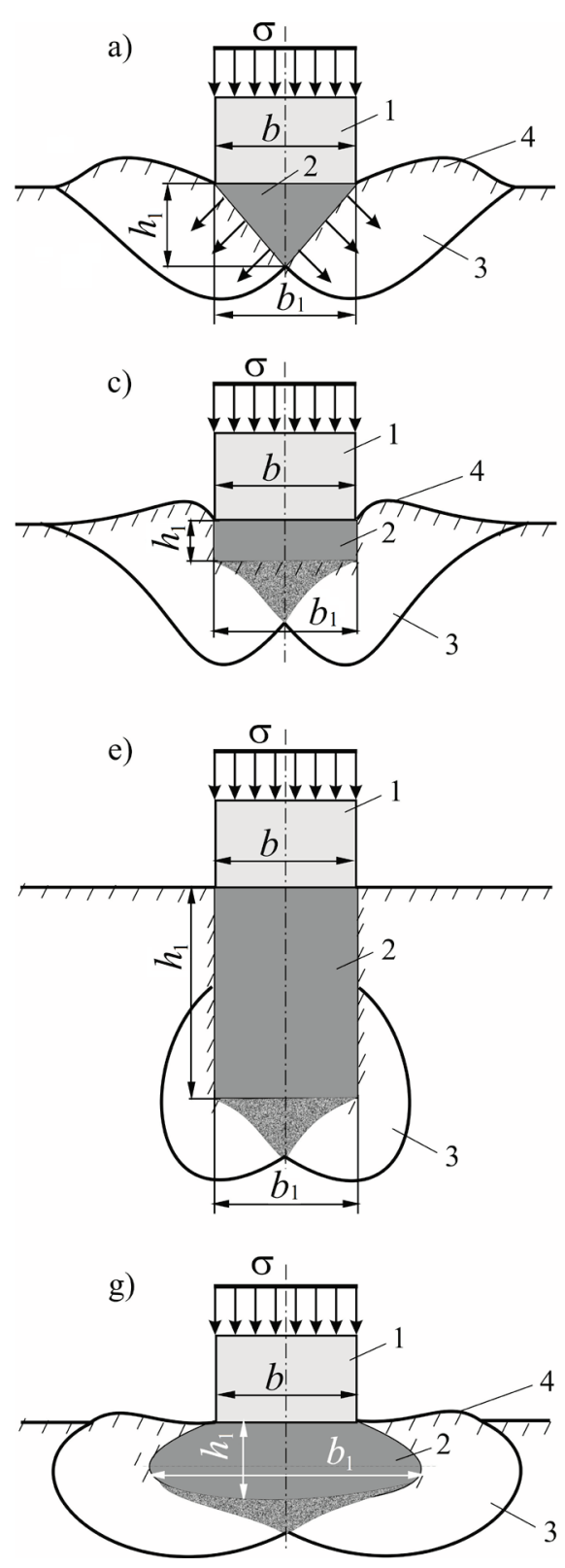
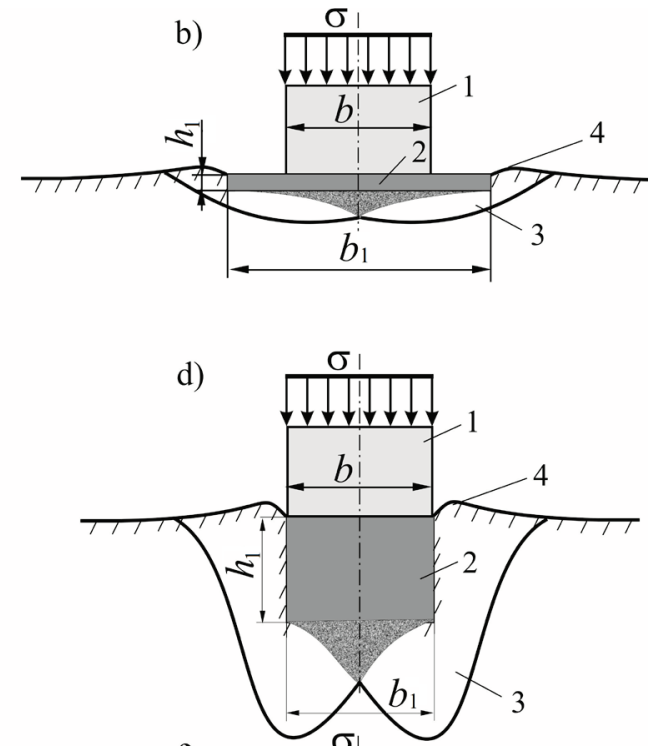

f)
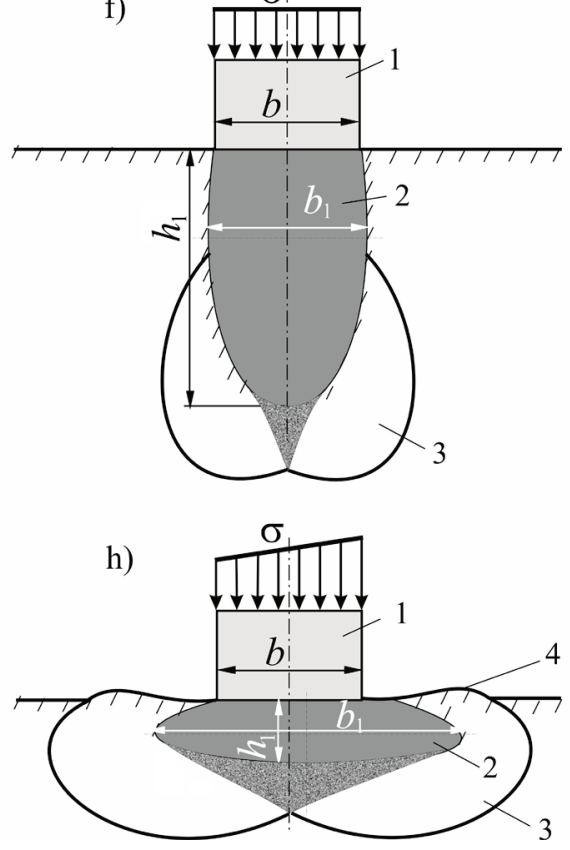

Fig. 1. Arrangements of protection 1 over local reinforced zones 2 with different shapes and deepening ( $\mathrm{a}$ - triangular, $\mathrm{b}$ - plate zone, $\mathrm{c}$ - rectangular shallow, $\mathrm{d}$ - rectangular of medium depth, $\mathrm{e}$ - rectangular of deep deposit, $\mathrm{f}$ - elliptical vertical of deep deposit, $\mathrm{g}$ - elliptical horizontal of average depth, $\mathrm{h}$ - elliptical horizontal of average depth with an offset axis, 1 - protection, 2 - local reinforced zone, 3 - area of limited equilibrium, 4 - protrusion shaft, $\sigma$ and $b$-respectively, a load on the modus of protection and its width, $h_{1}$ and $b_{1}$ - respectively, the height and width of the local reinforced zone).

Determination of the optimal parameters of local zones comes to the establishment of optimal shapes and linear dimensions, provided the resistance of protective means. To do this, it is accepted that the protective means are steady loaded and the rigidity of the local 
reinforced zone is equal to the rigidity of the protective material. Thus, the means of protection and the area under it can be considered as a holistic construction.

A great influence on the stability of soils has the depth of foundation [12]. When classifying foundations as a basis, the ratio of the depth of their laying $d(\mathrm{~m})$ to the width $b(\mathrm{~m})$ is taken. Therefore, the shallow foundations correspond to the ratio $d / b<0.5$, the average laying depth is $0.5 \leq d / b<2$, the deep $-2 \leq d / b \leq 4$ and the very deep laying $d / b>4$. We apply this classification for local reinforced zones in conditions of soft rocks footwall.

When determining the magnitude of the deepening of the local reinforced zone, the formulation of the problem was simplified, and it was accepted that the protective means and the local zone represent a holistic construction of width $b$. That is, the means of protection had a deepening relative to the surface of the footwall.

This problem can be solved on the basis of physical and numerical modeling. For physical modeling, a method of using equivalent materials is applied, and for numerical modeling - a finite element method. These methods are widely used to investigate the processes around underground roadways [3, 5, 13-20].

The conditions for mining the seam $\mathrm{c}_{18}$ of Shakhtoupravlinnia "Pivdennodonbaske No. 1" mine [21] were simulated on flat physical models with putting equivalent layers (sand-rosin-paraffin), model loading, extraction of roadways and a "breakage face" between them with the fastening and protection means setting (Fig. 2, 3). Strips made of brass foil were used for walling the roadways, and foam polystyrene was used for walling the face. Protective means in various models were simulated by parallelepipeds made of wood and polystyrene with compliance from 0 to $44 \%$.

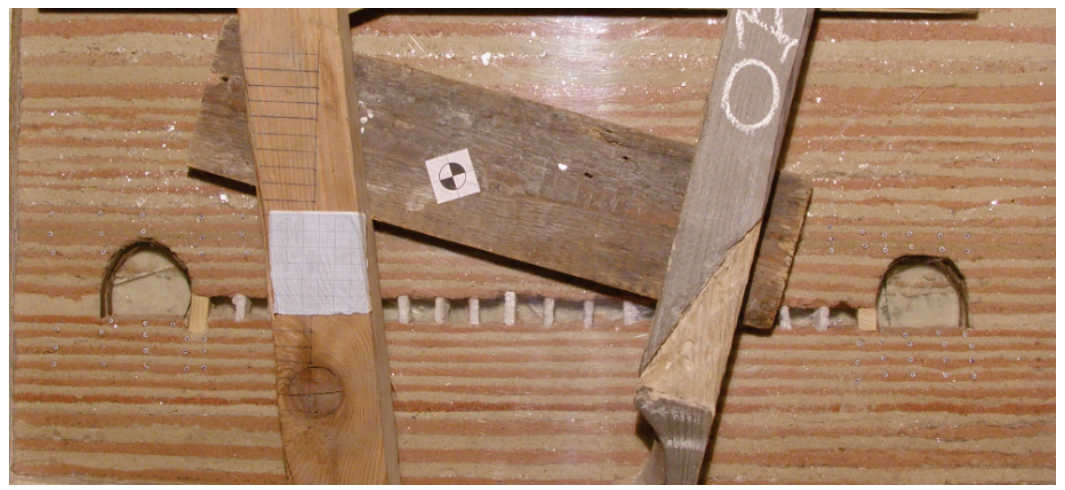

Fig. 2. General view of the model workspace.
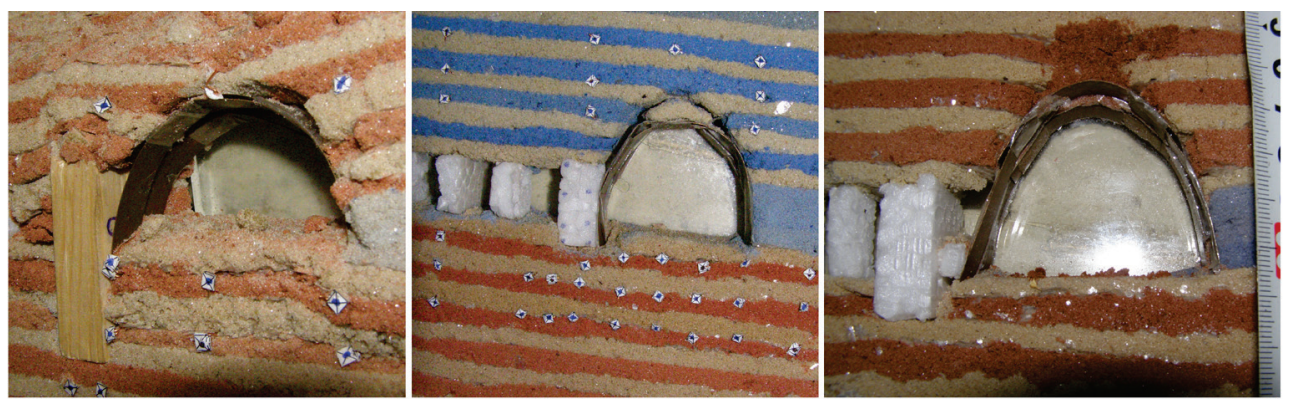

Fig. 3. General view of the roadways and protective constructions in the models.

To simulate the modelling of strata pressure, a stand was used, which was a rigid frame construction with internal working dimensions of $0.9 \times 0.55 \times 0.03 \mathrm{~m}$, which were covered with silicate glass on the front and back sides. The scale of the simulation was 1: 100 . 
During testing, the models were under constant load, the result of which was the deformation of the rock layers, the roadway circuit, as well as the means of fastening and protection.

To confirm the results by modeling with equivalent materials for conditions of the $\mathrm{c}_{18}$ seam, a numerical simulation was carried out in which the Mohr-Coulomb Model, based on the Hooke law and the Coulomb-Mohr thickness criterion, was used to implement the nonlinear nature of the massif deformation [22], which for the mining rock had the form, respectively

$$
\sigma=\varepsilon E
$$

and

$$
\tau=c+\sigma_{n} \tan \varphi
$$

where $\sigma$ - strain, $\mathrm{MPa} ; \varepsilon$ - rate of deformation; $E$ - elastic moduli, MPa; $\tau$ - shearing strain, $\mathrm{MPa} ; \sigma_{n}$ - normal strain, $\mathrm{MPa} ; c$ - adhesion, $\mathrm{MPa} ; \varphi$ - angle of internal friction, degree.

In the finite element method, a massif is modeled by a quasidiscrete model of a finite number of elements interconnected at nodes. Between nodal forces and displacement, a relationship is established by the dependence [23]

$$
\{\mathbf{f}\}=\left[K^{\prime \prime}\right]_{i}\{\mathbf{U}\}_{i}
$$

where $\{\mathbf{f}\}_{i}$ - nodal force vector of i- element, $\mathrm{N} ;\left[K^{\prime \prime}\right]_{i}$ - stiffness matrix of i- element, $\mathrm{N} / \mathrm{m} ;\{\mathbf{U}\}_{i}$ - nodal displacement vector of $\mathrm{i}$ - element, $\mathrm{m}$.

For the entire model, a stiffness matrix of a system is compiled in accordance with the expression

$$
\{\mathbf{F}\}=\left[K^{\prime \prime}\right]\{\mathbf{U}\},
$$

where $\{\mathbf{F}\}$ - nodal force vector of the system, N; $\left[K^{\prime \prime}\right]$ - stiffness matrix of the system, $\mathrm{N} / \mathrm{m} ;\{\mathbf{U}\}$ - nodal displacement vector of the system, $\mathrm{m}$.

The elastic solution is achieved by converting to the stress and deformation of the elements of nodal forces and displacement for the entire studied area. The elastic-plastic solution is achieved by numerous repetitions of elastic solutions with a directed change in the values of nodal forces with a constant stiffness of the system [22].

There were five models of the massif built, which differed from each other in the depth of the protective means (from 0 to $3 \mathrm{~m}$, which corresponded to the $d / b$ ratio from 0 to 3 where $b=1 \mathrm{~m}$ ). A general view of one of the models at the stages of its construction and calculation is shown in Figure 4.

\section{Results and discussion}

Analysis of the simulation results (Fig. 5, 6) showed that the displacement of the rocks on the mine circuit with different parameters of the protective means was not the same. When working out the models, a loss in the cross section of the roadways was observed to a greater extent due to displacement of the roof rocks. It has been established that building the protective construction with its laying below the surface of the footwall makes it possible to reduce the displacement in the roadway and maintaining its cross section at the level of $76 \%$ of the original. For example, in models № 1 (Fig. 5 a) and № 2 (Fig. 6 a) the 
means of protection were rigid with the same size ratio $b / h=0.5$ ( $b$ and $h$ - respectively, width and height of protection means, m), but different in height above the footwall $h_{n}(\mathrm{~m})$ (respectively, $b / h_{n}=1$ and $b / h_{n}=0.75$ ). Their drilling in the foot rocks amounted to, respectively, $d=0.5 b$ and $d=b$, the residual cross section was almost the same $\left(S_{1 l}=0.76 \ldots 0.77 S_{1 f}\right)$, but the proportion of displacement of roof rocks in the roadway in general convergence was slightly different and amounted to, respectively, 77.7 (Fig. 5 a) and $85.4 \%$ (Fig. 6 a).

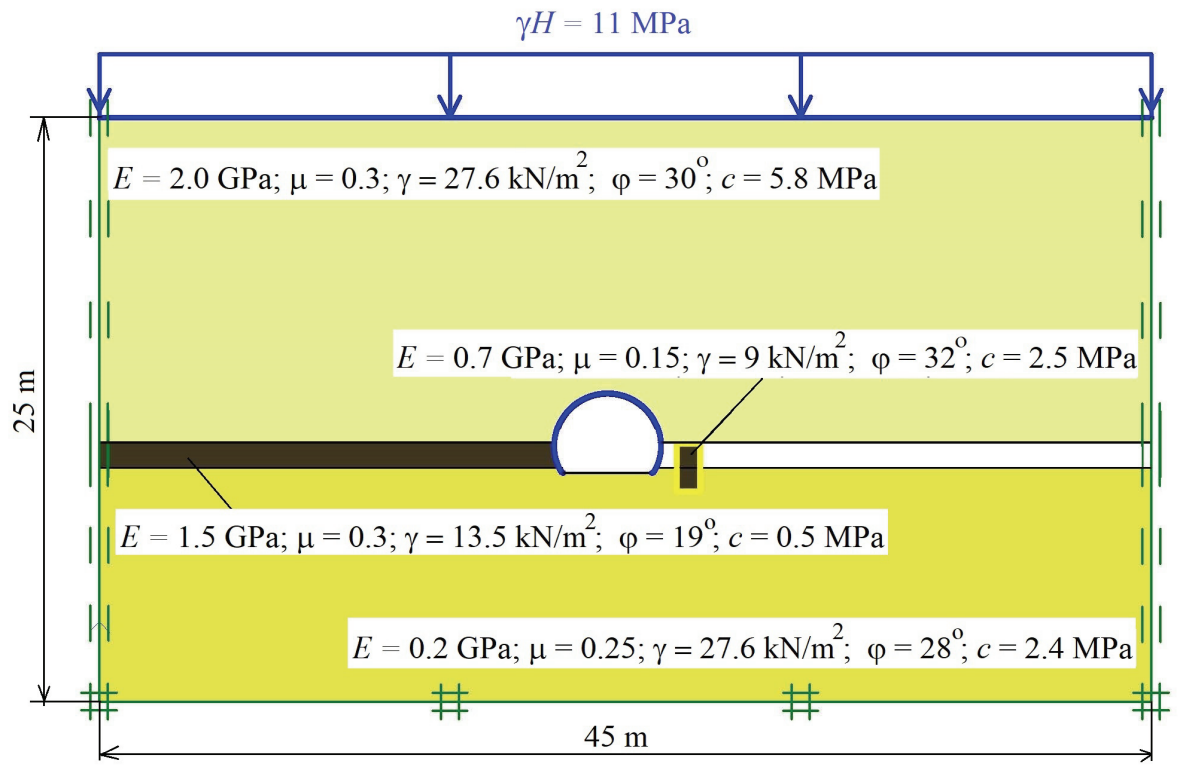

Fig. 4. General view of the numerical model at the stage of its construction ( $E$ - elastic moduli; $\mu-$ the Poisson coefficient; $\gamma$ - volume weight; $\varphi$ - angle of internal friction; $c$-adhesion; $H$ - depth of work).

For roadways that were protected without deepening (Fig. $5 \mathrm{~b}-b / h=b / h_{n}=0.67$; Fig. $\left.6 \mathrm{~b}-b / h=b / h_{n}=0.75\right)$, but with different flexibility, the cross-sectional areas decreased by 36 and $51 \%$, and the worst indicator related to the rigid pack (Fig. 6 b). The large loss in cross section in both roadways was due to significant roof displacement, whose shares of the total convergence for models №1 and №2 were, respectively, 81 and 89.7 \%. It should be noted that when protected by a more rigid construction, it pierced the underlying rocks by $17.5 \%$ of the height of the protecting construction. When the pack was flexible the piercing was not observed. It is the stiffness of the construction that is the most likely cause of the worst state of roadway, since it is above this construction and below it that you can see the deformation zones of the adjoining rocks (Fig. 6 b).

The development of similar models with various parameters of protective means made it possible to establish graphs of the dependence of the residual cross-sectional area of the roadways on the load time of these models (Fig. 7) and a graph of the dependence of the residual cross-section on the magnitude of deepening of the protective constructions (curve 1, Fig. 8). From the graphs it follows that the worst state of roadway in conditions of soft rock foot is in the absence of deepening of the protective construction, and the best when it is deepened by $0.8 b$ (Fig. 7). As a result, we can recommend the value of the construction deepening $1.0 b$ (Graph 1, Fig. 8), and with a $5 \%$ deviation, the range is from $0.45 b$ to $1.75 b$. With a deepening of more than $1.75 b$, the worst result was obtained due to the offset increase of the roof rocks in the roadway. A similar result was obtained by numerical modeling of the state of a trapezoidal roadway, which was protected by a cast 
strip, as described in [24]. According to this study (Graph 2, Fig. 8), the recommended deepening is $1.2 b$ in the effective range from $0.62 b$ to $1.72 b$.

a)
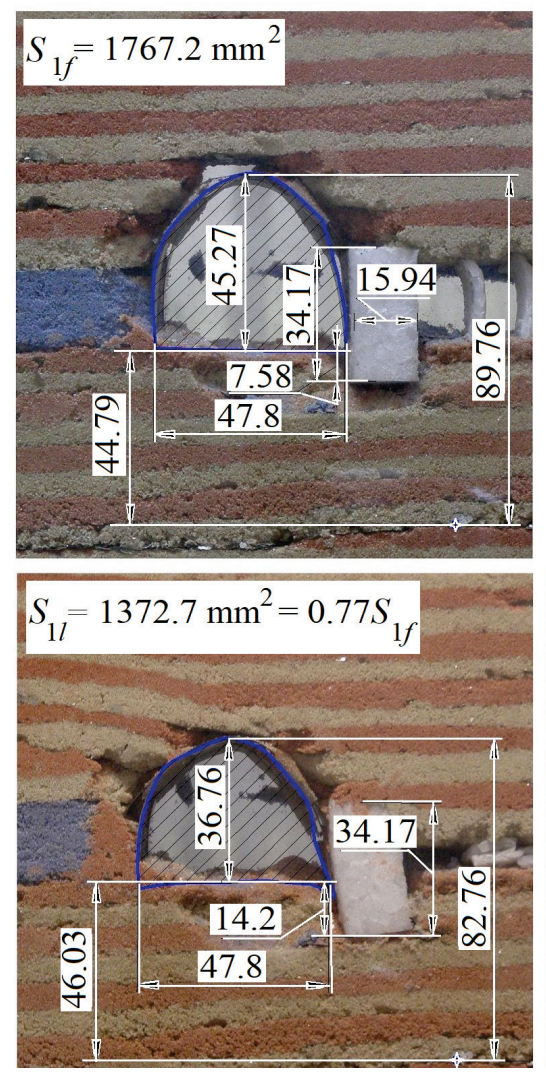

b)
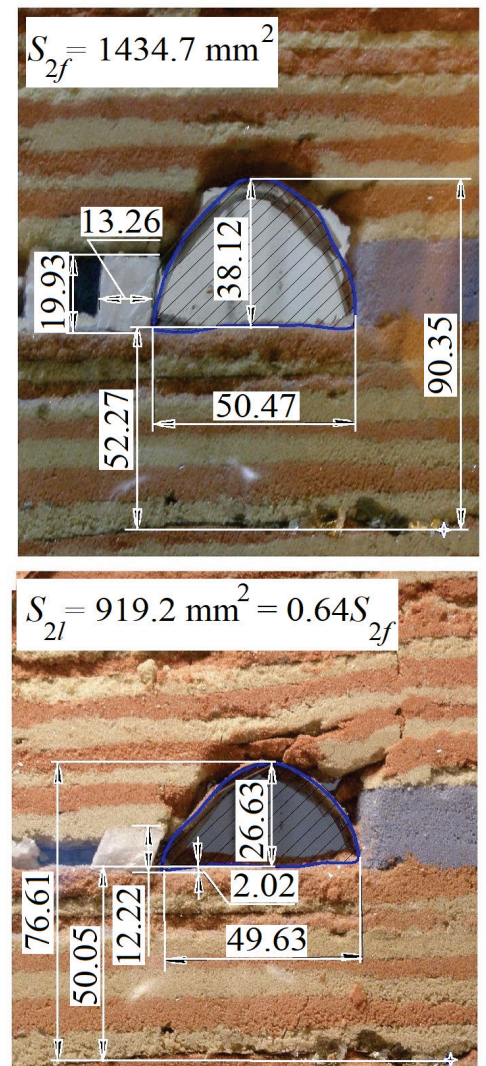

Fig. 5. General view of protective constructions and roadways located on the left (a) and on the right (b) in model №1, at the beginning $\left(S_{1 f}\right.$ and $\left.S_{2 f}\right)$ and at the end $\left(S_{1 l}\right.$ and $\left.S_{2 l}\right)$ measurements of their cross sections.

When developing numerical models for conditions of the $\mathrm{c}_{18}$ seam, the deformed grids have been obtained (Fig. 9), from which it is possible to determine the cross-sectional areas of the roadway before and after calculation, as well as the relative value of the change in the residual section depending on the magnitude of deepening of the protective means.

Based on the calculation results, the values of the relative residual sections of the roof shape have been established, with its protection with a holistic wooden construction having varied its deepening relatively to the foot. This has confirmed the results of physical modeling, namely: an insignificant deepening of the protective means on soft rock foot allows saving the residual roadway area of more than $82 \%$ (Fig. 9), the best result has been achieved by deepening the construction by $0.8 b$ (Graph 3, Fig. 8), but a significant deepening of the construction is not advisable, because it does not lead to a significant improvement in the state of roadway. Thus, the average depth can be considered rational, according to the classification of foundations [12], but with an adjustment of the minimum depth of the range to $0.8 b$.

When testing the models, another feature was noted, which consisted in the fact that most of the protective means as a result of the load was piled on top towards the roadway, regardless of the compliance, width and deepening of the construction. This is explained by 
the asymmetric load of the protective construction as a result of radial lowering of the roof rock layers relatively to the break line of the main roof rocks, and is considered in [7].

a)
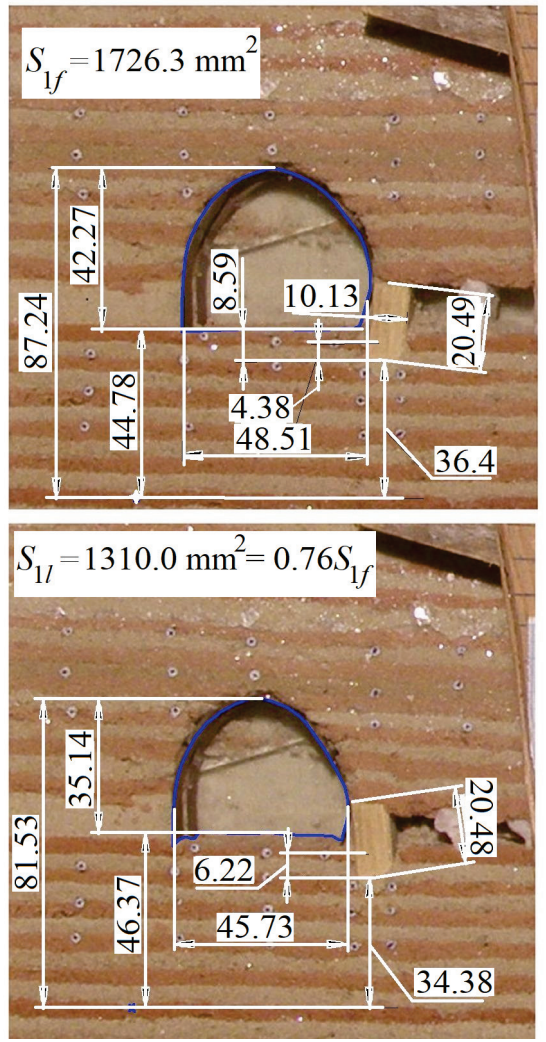

b)
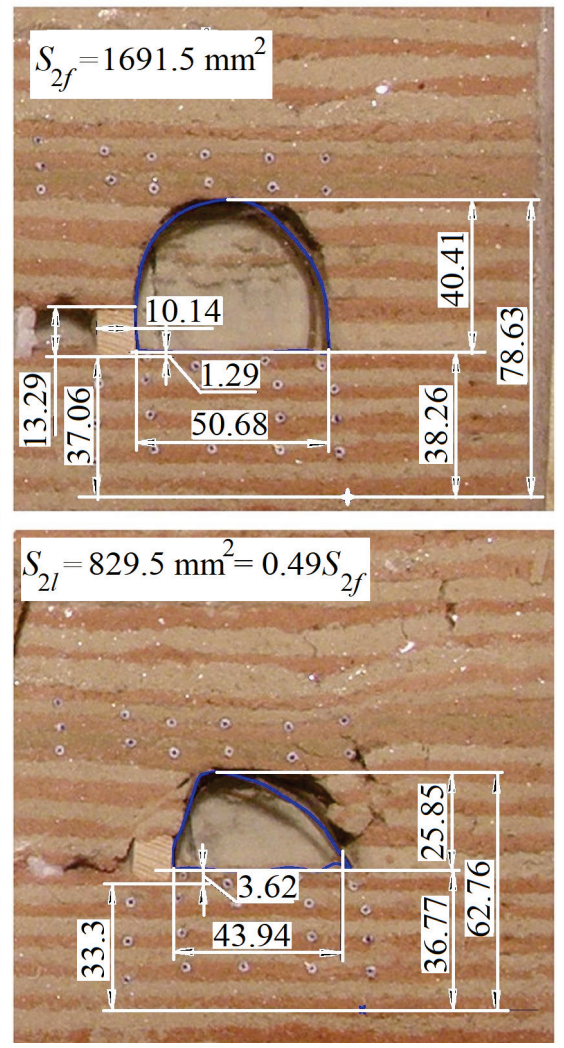

Fig. 6. General view of protective constructions and roadways located on the left (a) and on the right (b) in model № 2, at the beginning $\left(S_{1 f}\right.$ and $\left.S_{2 f}\right)$ and at the end $\left(S_{1 l}\right.$ and $\left.S_{2 l}\right)$ measurements of their cross sections.

Evaluation of the distribution of vertical loads along the lines A-A * and B-B * in the models with deepening and without it (Fig. 10) shows, that the load on the protective construction is really asymmetric, but at the level of the foot surface the loads can be considered to be steady (especially when deepening). They constitute, respectively, 90 and $92 \%$ of the maximum load along the line A-A *. Parts of the protective means that are above and below the surface level of the underlying rocks are deformed in different ways, but the largest displacement occurs in the upper part. That is, these parts must be considered separately, not as a holistic construction.

The imprecision between the results of physical and numerical simulations ranged from 5 to $22 \%$. This is due to the fact that with equivalent modeling, protective constructions with different compliance were investigated, but with numerical - with the fixed one. Besides that, in some physical models, the width of the protective means and the seam thickness were slightly different. Therefore, it can be argued that in order to obtain the most complete picture of the deformation of the rocks around the roadway, it is necessary to take into account such parameters as: compliance (stiffness), the width of the construction and its height above the sole level. It is also proposed to take into account the stiffness of the underlying rocks, since this factor is a key in determining their rigidity. 


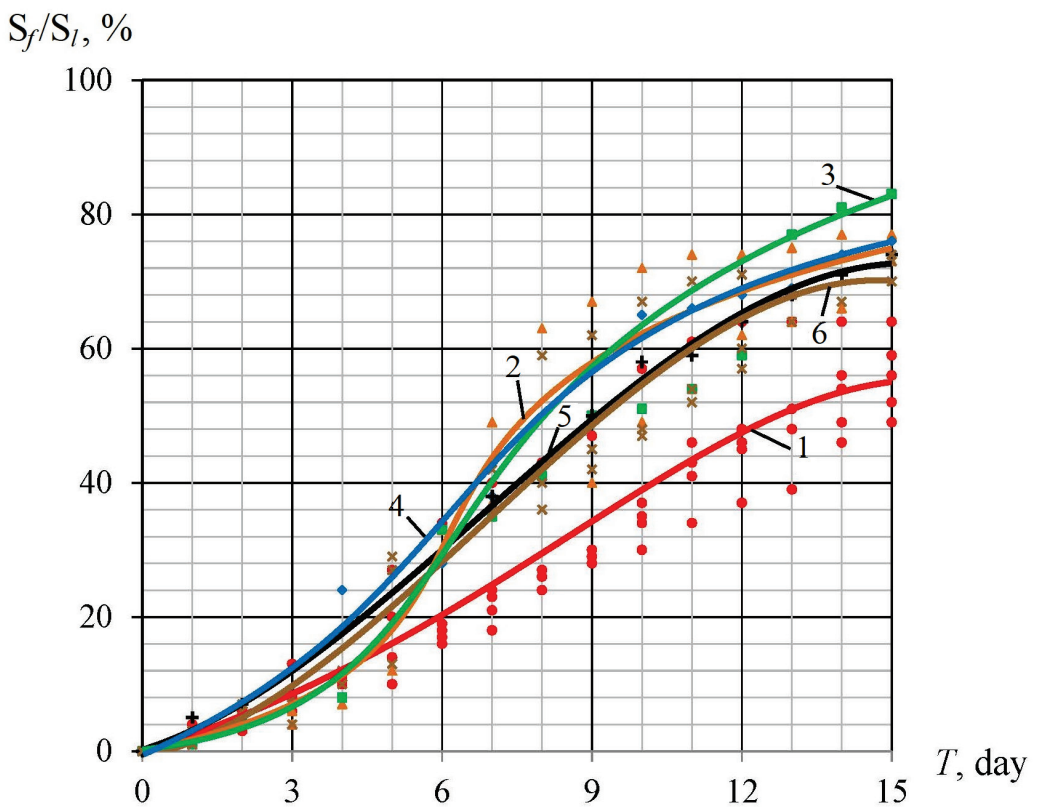

Fig. 7. Graphs of the dependence of the relative areas of the residual cross-sections $S_{f} / S_{l}$ of the roadways on the time of working out of physical models $T$ with different parameters of protecting means $(1-d=0 ; 2-d=0.5 b ; 3-d=0.8 b ; 4-d=1.0 b ; 5-d=1.3 b ; 6-d=2.0 b ; \bullet, \times,+, \Delta, \bullet,--$ the markers according to the results of measurements on the models with different parameters of protective means, correspond to the graphs $1,2,3,4,5,6)$.

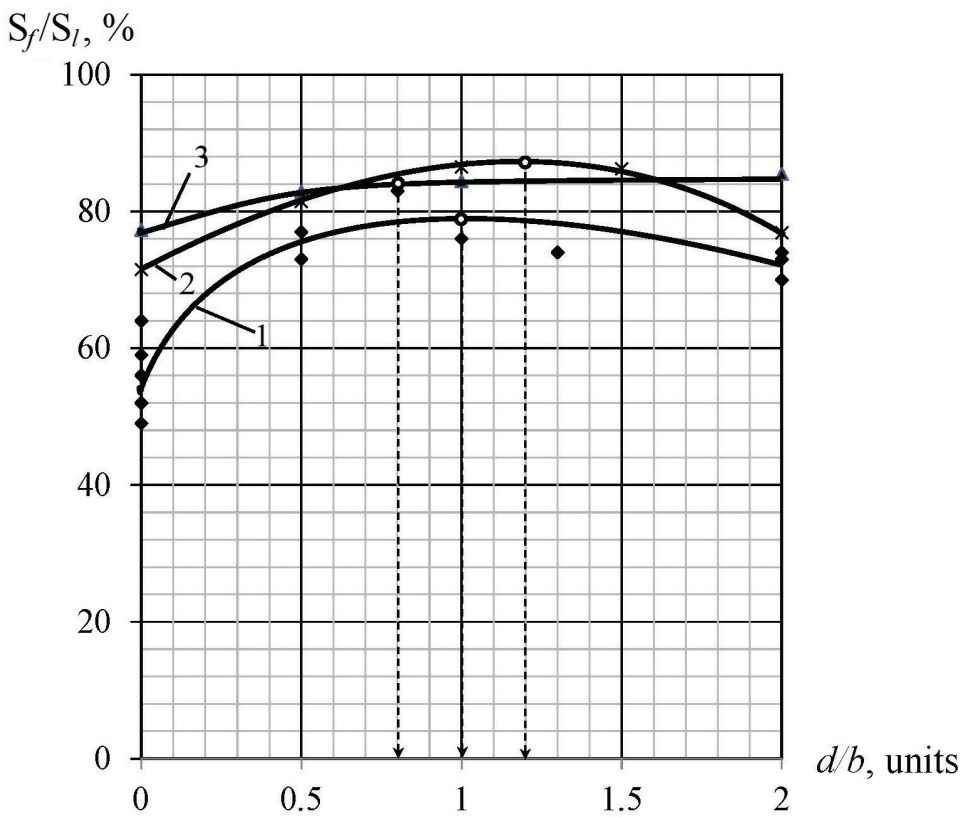

Fig. 8. Graphs of changes in the residual cross-section of the roadway $S_{f} / S_{l}$ depending on the magnitude of the deepening of the protective construction $d / b$ according to the results of physical (1) and numerical $(2,3)$ simulations $(\bullet, \mathbf{x}, \mathbf{\Delta}-$ the markers according to the measurement results, correspond to the graphs 1,2,3). 

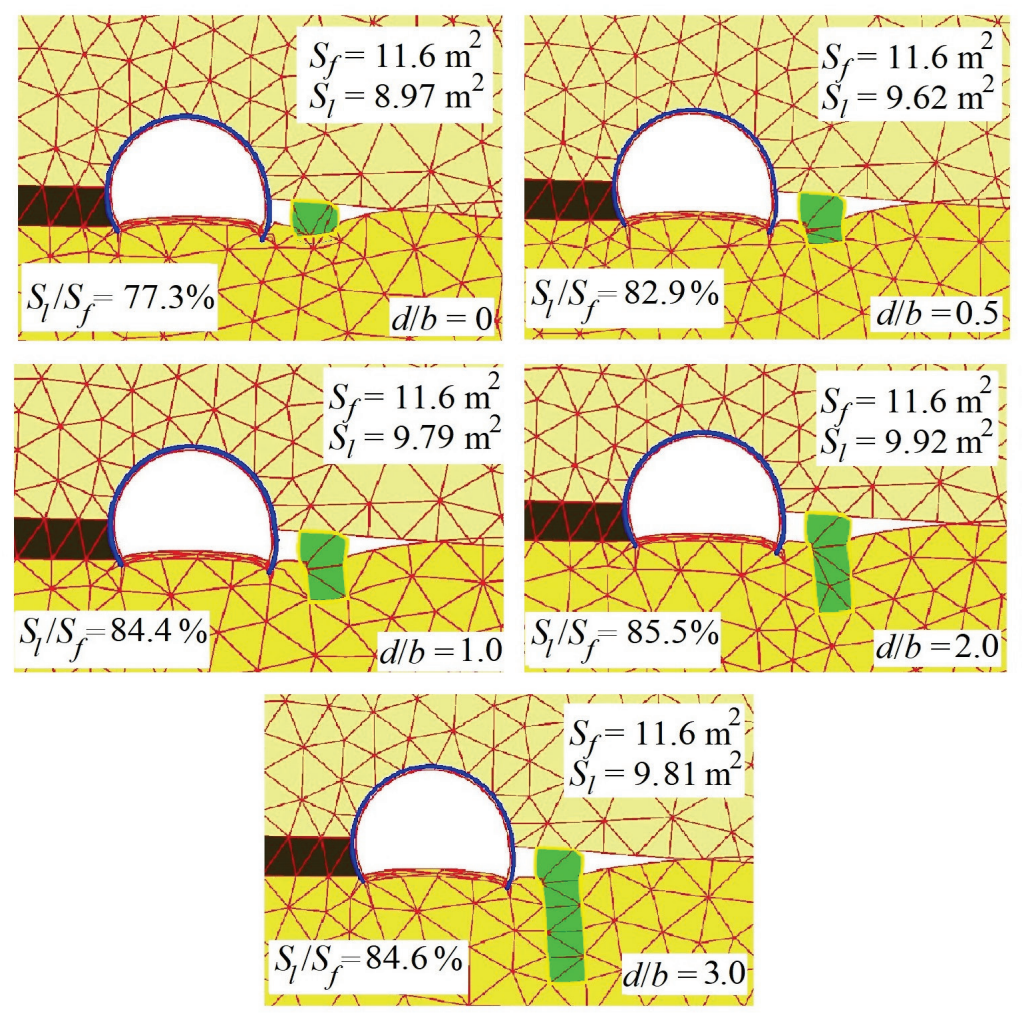

Fig. 9. General view of deformed grids of finite element models with different relative values of the deepening of the protection $d / b$ ( $d$ - the depth, $b$ - the width of protection) to determine the relative residual cross-section of the roadway $S_{k} / S_{n}\left(S_{n}, S_{K}\right.$ - the cross-sectional area of the roadway, respectively before calculating models and after it).

\section{Conclusions}

As a result of the simulation, the following conclusions have been made:

- the use of rigid protective constructions without additional measures to ensure the stability of soft underlying rocks is inefficient, since the protective means are not just pressed into these rocks, but also causes contortion of the roof rocks over it;

- building the protective construction below the sole surface allows reducing displacement in the roadway and save its residual area of more than $82 \%$;

- the average laying depth of the local reinforced zone in the range of $0.8 \leq d / b<2$ can be considered as effective one;

- protective means take an asymmetric load from the roof rocks, which turns into a steady load, and for $90 \%$ is transferred to the underlying rocks or reinforced zone;

- to establish the rational parameters of the local reinforced zone under the protective means, it is enough to be limited with the ones that determine the stress state of the underlying rocks, namely: thickness and deformation characteristics of this zone under the protective means, its shape, depth and width, as well as the characteristics of the sole rocks.

This work was carried out within the framework of the project "Improvement of ways to increase the stability of mine workings in deep mines" (State registration No. 0117U004316). 
a)
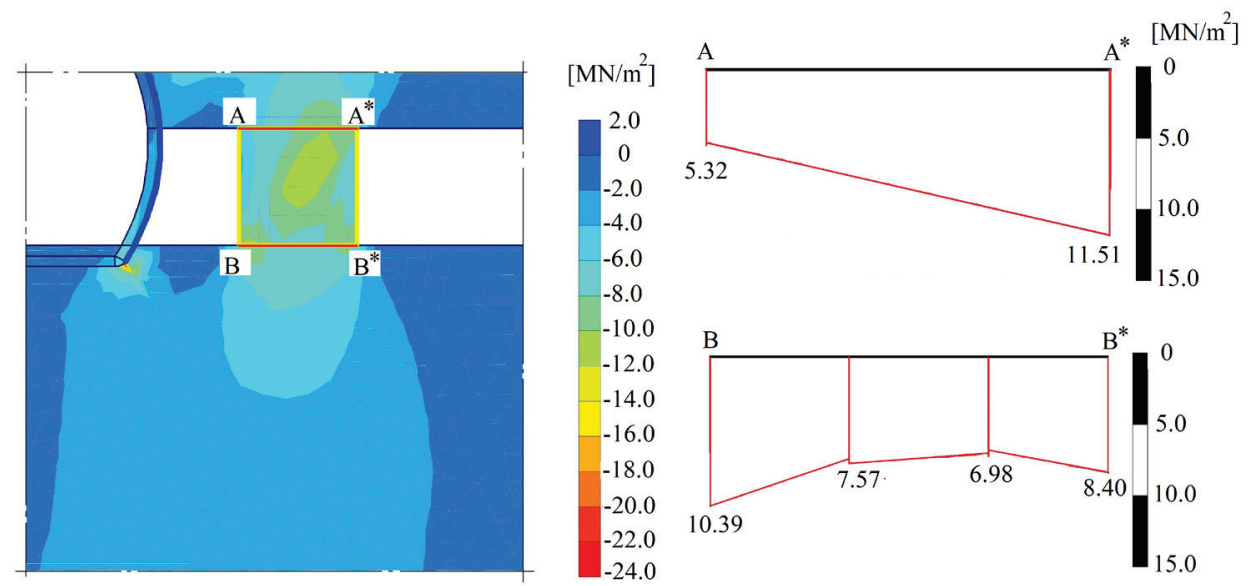

b)
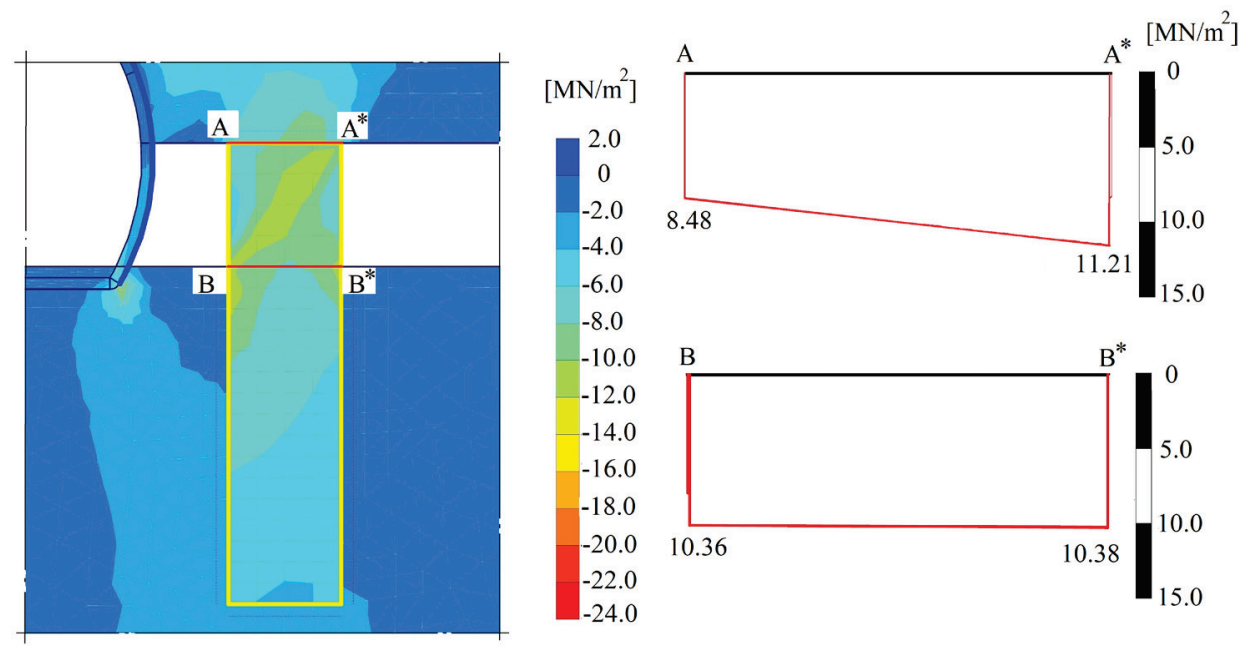

Fig. 10. General patterns of the distribution of vertical strains around protective means without a deepening (a) and with a deepening (b) in the underlying rocks.

\section{References}

1. Nehrii, S., Nehrii, T., Bachurin, L., Piskurska, H. Problems of mining the prospective coal-bearing areas in Donbas. E3S Web Conf. Ukrainian School of Mining Engineering, 123 (2019). https://doi.org/10.1051/e3sconf /201912301011

2. Borzyh, A.F., Skrypnik, K.E., Trofimov, E.V., Posohov, E.V. (2015). Ohrana vyemochnyh vyrabotok s pomoshchyu tehnologicheskih tselikov. Coal of Ukraine, 5, 311

3. Baysarov, L.V. (2004). Parameters ground and the combined method technology development of support of repeatedly used working. Dr. PhD Tech. NMU, Dnepropetrovsk

4. Borzyh, A.F. (1998). Razrabotka sposobov ohrany podgotovitelnyh vyrabotok pri otrabotke pologih ugolnyh plastov vostochnogo regiona Ukrainskogo Donbassa. Dr. Sci. Tech. DonSTU, Donetsk 
5. Bondarenko, V.I., Kovalevska, I.A., Symanovych, H.A., Koval, O.I., Fomichov, V.V. (2012). Eksperymentalni doslidzhennia stiikosti vyimkovykh vyrobok, yaki povtorno vykorystovuiutsia na polohykh plastakh Donbasu. Dnipropetrovsk: LizunovPres

6. Dimanshteyn, A.S., Lisichkin, V.G., Mininberg, V.Ya., Hutornoy, V.F. (1982). Issledovanie deformatsiy vyemochnyh vyrabotok pri razlichnyh sposobah ih ohrany. Coal of Ukraine, 10, 3-5

7. Nehrii, S. (2019). Determination of displacement the roof of the mining workings in the zone of influence of longwall face. Journal of Donetsk Mining Institute, (44), 41-52. https://doi.org/10.31474/1999-981x-2019-1-41-52

8. I. Farmer. Coal mine structures. Chapman and Hall, London (1985). http://doi.org/ 10.1007/978-94-009-4834-1

9. Kasyan, N.N. (2002). Geomechanical basis of management of a zone of the destroyed rocks around of roadway for maintenance of their stability on the big depths: Dr. Sci. Tech. DonNTU, Donetsk

10. Isaenkov, O., Sahno, I. (2017). Substantiation parameters of local soil strengthening consolidation of breeds with extensible mixtures. Journal of Donetsk Mining Institute, 1(40), 35-40. https://doi.org/10.31474/1999-981x-2017-1-35-40

11. Sahno, I., Isaenkov, O., Liashok, Y., Rodzin, S. Sposib ukriplennia pidoshvy hirnychoi vyrobky. Patent No 116603, Ukraine

12. Shvetsov, G.I., Noskov, I.V., Slobodyan, A.D., Goskova, G.S. (1991). Osnovaniya $i$ fundamenty. Spravochnik. Moskva: Vyisshaya shkola

13. J. Guo, G. Feng, P. Wang, T. Qi, X. Zhang, Y. Yan. Roof Strata Behavior and Support Resistance Determination for Ultra-Thick Longwall Top Coal Caving Panel: A Case Study of the Tashan Coal Mine. Energies, 11, 1041. (2018). http://doi.org/10.3390/en11051041

14. G. Li, S. Cao, F. Luo, Y. Li, Y. Wei. Research on mining-induced deformation and stress, insights from physical modeling and theoretical analysis. Arabian Journal of Geosciences, 11, 1-9. (2018). http://doi.org/10.1007/s12517-018-3422-9

15. R. Gao, B. Yu, H. Xia, H. Duan. Reduction of Stress Acting on a Thick, Deep Coal Seam by Protective-Seam Mining. Energies, 10, 1209. (2017). http://doi.org/10.3390/en10081209

16. C.O. Aksoy, G. Gulsev Uyar. Non-deformable support system in swelling and squeezing rocks. Rock Mechanics and Engineering, 4: Excavation, Support and Monitoring. 179-203. (2017)

17. N. El. Houari, M.A. Allal and N. Abou Bekr. Numerical Simulation of the Mechanical Response of the Tunnels in the Saturated Soils by Plaxis. Jordan Journal of Civil Engineering, 5, 1, 9-31. (2011)

18. M. Hilar, V. John. Numerical modelling of the brezno tunnel re-excavation. ECCOMAS Thematic Conference on Computational Methods in Tunnelling (EURO:TUN 2007) J. Eberhardsteiner et.al. (eds.) Vienna, Austria, August 27-29, 2007

19. N. Radouane, M. Boukelloul, M. Fredj. Stability Analysis of Underground Mining and their Application on the Mine Chaabte El Hamra, Algeria. Procedia Earth and Planetary Science, 15, 237-243. (2015). https://doi.org/10.1016/j.proeps.2015.08.058

20. Sakhno, I.G. (2014). Impact of rigidity of a protective construction on the stress-strain state of the rock mass around the roadways supported after the longwall. Geo-Technical Mechanics, 115, 176-187

21. Nehrii, S., Sakhno, S., Sakhno, I., Nehrii, T. Analyzing kinetics of deformation of boundary rocks of mine workings. Mining of Mineral Deposits, 12, 4, 115-123. (2018). https://doi.org/10.15407/mining12.04.115

22. Fadeev, A.B. (1987). Metod konechnyh elementov v geomehanike. Moskva: Nedra. 
23. Bondarenko, Yu.V. (1991). Nauchnye osnovy bezlyudnoy i bezothodnoy tehnologii vyemki vesma tonkih pologih plastov. Dr. Sci. Tech. DPI, Donetsk

24. Nehrii, S., Rikhert, S.V. (2016). Opredelenie parametrov zhestkikh okhrannykh sooruzheniy v usloviyakh slabykh vmeshchayushchikh porod. Materialy konferentsii "Perspektivy razvitiya stroitelnykh tekhnologiy", 96-100 